liche Netze von Pigment in allerlei Gestalten zwischen den Epitheliumzellen. Je näher man nach dem oberfächlichen Pflasterepithelium hin kömmt, desto mehr verschwindet das Pigment aus der Intercellularsubstanz; dort jedoch trifft man es deutlich in den Epitheliumzellen selbst an und, wie auch Aeby angiebt, oft sehr charakteristisch halbmondförmig um die Kerne an der Seite, welche nach der freien Oberfläche des Corneaepitheliums hin gewendet ist. Ich glaube, dass dieser Ausdruck: „nach der freien Oberfläche der Epitheliumschicht zu" besser ist als der Aeby's, wo er sagt: ,in der Hälfte der Zelle, welche vom Bindegewebe abgewendet ist". Es scheint mir wohl, dass die Ursache dieser Thatsache in dem Verhältniss des Pigmentes zum Lichte liegt. Das Pigment bewegt sich stets nach dem Lichte zu und muss sich also in den Corneaepitheliumzellen in diejenige Hälfte der Zelle, welche der Lichtseite zugekebrt ist, also nach der freien Oberfläche zu, begeben.

\title{
2.
}

\section{Ein Fall von Zwerghaftigkeit als Beitrag zur Aetiologie der Wachsthumshemmung.}

\author{
Von Dr. F. Rohrer in Zürich.
}

Abgesehen von der relativen Seltenheit der Zwerghaftigkeit bietet nachstehender Fall Interesse durch die zweifellose Coincidenz traumatischer Einwirkungen auf Gehirn und Rückenmark mit der Wachsthumshemmung. Der 20 Jahre alte A. H. präsentirt sich als ein ziemlich proportionirt gebautes mageres Bürschchen mit ältlichem, nicht besonders intelligentem Gesichtsausdruck. Der Vater war ein grosser und starker Mann (soll syphilitisch gewesen sein); die Mutter starb 45 Jahre alt an Phthịis pulmonum; sie war eine grosse Fran. Ein Bruder starb 8 Wochen alt an Convulsionen. Ein Bruder lebt, ist 22 Jahre alt, schlank und gross, $171 \mathrm{~cm}$ Körperlänge. Der Zwerg A. H. ist gegenwärtig $120 \mathrm{~cm}$ lang. Derselbe kam als normalgebildetes Kind zur Welt und entwickelte sich normal, bis wiederholt schwere Traumen auf den Kopf einwirkten. Im 2. Jahr Fall auf den Kopf gegen einen Nachttopf, im 11. Jahr Fall über eine Kellertreppe und im gleichen Jahr Beilbieb auf den Scheitel mit nachfolgender längerer Eiterung. Seither leidet Patient an Incontinentia urinae und blieb Wachsthum und Entwicklung stabil. Die Stimme ist ganz kindlich geblieben, - Knabensopran. Sinnesorgane sind gut entwickelt und besteht etwas Myopie. Sexualorgane präsentiren sich in ganz unentwickeltem Zustand, ungefähr wie bei einem Knaben von 5-7 Jabren. Keine Spur von Crines; Penis vom Präputium weithin bedeckt, ganz rudimentär entwickelt, Testikel beiderseitig in Grösse dor frühen Entwicklungsstufe gleich. 